\title{
FASCIOLÍASE HEPÁTICA HUMANA: NÔVO CASO AUTÓCTONE *
}

\author{
Marcelo Oswaldo Alvares Corrêa** e Gilda Corrêa Fleury**
}

\begin{abstract}
Os AA. relatam mais um caso humano autóctone de fascioliase hepática provàvelmente contraída em Cornélio Procópio, Paraná. As curas clinica e parasitológica foram alcançadas através da administração de arágeas contendo dez miligramas de deidroemetina (Ro-1-9334/20) na dose de cinco drágeas por dia, durante dez dias.
\end{abstract}

\section{INTRODUÇÃO}

O interêsse do presente caso reside no registro de mais um caso autóctone e no tipo de terapêtica instituída.

De acôrdo com Mattar Filho e Amaral (3) que, a propósito de caso humano de fasciolíase hepática não autóctone, fizeram completa revisão do assunto, cabe a Rey e col. o encontro do primeiro caso humano autóctone de fascioliase hepática correspondente a uma criança de três anos de idade, de Campo Grande, Estado de Mato Grosso. Santos e Vieira (5) relataram o encontro de sete casos de fasciolíase humana no Vale do Paraíba, Estado de São Paulo; finalmente Santos e col. em 1967, segundo referem Mattar Filho e Amaral, encontraram em Ilhéus, Bahia, mais dois pacientes em cujas fezes foram diagnosticados ovos de Fasciola hepatica.

O número total de casos autóctones humanos de fasciolíase registrados entre nós até a data atual é pois de dez, constituindo-se assim o caso ora apresentado no décimo-primeiro da série.

Ao 18..$^{\circ}$ Congresso Brasileiro de Higiene efetuado em São Paulo de 26 a 31 de outubro de 1970, Santos e França (6) comunicaram a descoberta de focos de caramu- jos do gênero Lymnea, transmissores da Fasciola hepatica, nos municípios de Pindamonhangaba ( 2 focos), Taubaté ( 3 fo$\cos$ ), Caçapava (3 focos), São José de Campos (1 foco), Natividade da Serra (1 foco). Tornou-se assim evidente que o Vale do Paraíba poderá vir a se constituir em intenso foco de fascioliase humana, pois lá existem o gado infectado (cêrca de 10\%), os caramujos transmissores (Lymnea) e cuitura de agrião, através de cuja ingestão as metacercárias alcançam o organismo humano.

E necessário, pois, que os médicos daquela região tenham em mente esta possibilidade para que possam chegar ao diagnóstico correto, em face do caráter proteiforme que assume o quadro clínico da fasciolíase humana.

Exemplo ilustrativo desta asserção encontra-se no relato de Hardman, Jones e Davies, intitulado "Fascioliasis - a large outbreak", onde informam que ao descobrir ovos de Fasciola hepatica nas fezes de um paciente, compreenderam que estavam atendendo diàriamente pacientes que tinham muitos sintomas de casos iniciais de fasciolíase. Recorreram então a recursos diagnósticos mais específicos e desde logo tornou-se evidente que um grande

* Trabalho apresentado ao XVIII Congresso Braslleiro de Higlene, Săo Paulo, 1970.

* Da Seção de Parasitologia do Instituto Adolfo Lutz (Săo Paulo).

Recebido para publicaçăo em 8.7.1971. 
surto desta rara doença estava grassando na comunidade (44 casos em Chespstow, Monmouthshire, Inglaterra) (2).

\section{RELATO DO CASO}

Irmã M.G.S. - 28 anos, branca, brasileira, solteira.

Nasceu em S. Pedro do Turvo, Estado de Săo Paulo. Aos 3 anos de idade, foi para Santa Cruz do Rio Pardo onde cresceu, estudou e ingressou como postulante em 1959. Em janeiro de 1963, foi para Cornélio Procópio onde a Ordem à qual pertence mantém um colégio, com alunos internos e externos. O Colégio possui uma chácara onde existe gado que bebe no ribeirão que percorre a propriedade, na qual existe agrião. A paciente costumava comer agrião tanto quando residia em Santo Cruz do Rio Pardo como em Cornélio Procópio. Cêrca de três anos depois de ter ido para esta cidade, começou a sentir dores nas costas, espáduas e ombro direito sem ritmo característico, pêso no estômago como se tivesse a digestão difícil, principalmente à tarde; mesmo que almoçasse pouco, ficava "empachada". Chegava a vomitar, como aconteceu uma vez, ocasião em que fêz exame radiológico dos pulmões e do estômago.

Em 3.7.68 fêz uma radiografia de vesícula que demonstrou colecistograma normal. Efetuou ainda, em julho de 1967, vários exames de fezes, sangue e urina, que não revelaram nada de particular. Consultou então um gastroenterologista que solicitou entubação duodenal, efetuada em laboratório particular, ocasião em que foram encontrados ovos identificados como sendo de Fasciola hepatica na Seção de Parasitologia do Instituto Adolfo Lutz. A pesquisa de ovos de $F$. hepatica, nas fezes da paciente, foi igualmente positiva.

Não fêz tratamento nenhum para êste fim nessa ocasião, pois retornou para Cornélio Procópio. Em fevereiro de 1969, cêrca de 18 meses depois, voltou a São Paulo para tratamento, registrando a mesma queixa digestiva, cansaço e febre vespertinos, a qual não passava de $38^{\circ} \mathrm{C}$.

Interrogatório sôbre os diferentes aparelhos: cefaléias frequentes, dores nas pernas como se fôsse cansaço. Resfriados freqüentes. Dorme bem. Inapetente.

Antecedentes pessoais: Foi operada do apêndice em 1958; amigdalectomia por duas vêzes; teve tracoma, conjuntivite, parotidite, amebíase e giardiase.

Exame físico: Paciente extremamente magra, mucosas pouco coradas com evidentes sinais de carência alimentar. Pele sêca e pouco elástica. Pêso: 45 quilos, altura $1,56 \mathrm{~m}$; PA $100 \times 60$. Ao restante do exame nada de anormal foi observado.

Exames subsidiários:

1 - Colecistografia:

"Vesícula biliar piriforme e alongada, bem contrastada, sem sinais de cálculo, respondendo satisfatóriamente à prova motora. Colecistograma presente e normal." 3.7.68 (a) Dr. Marcos F. Rezende.

2-Sôro-aglutinação para brucelose prova lenta (Instituto Biológico): Negativa desde 1:10 (24.8.67).

3-Prova de Sabin-Feldman: Negativa (26.6.67).

4 - Provas de função hepática (1.2.69): Determinação da transaminase glutâmico-oxalacética: 6 unidades Segma - Frankel (Método de RetmanFrankel com leitura espectrofotométrica) .

Sangue: determinação da bilirrubina total $-0,6 \mathrm{mg}$.

Reações de timol no sôro: Turvação: 1,5 unidades; Floculação: Negativa.

Hemograma (3.2.1969):

Eritrócitos $/ \mathrm{mm}^{3} \ldots \ldots \ldots 4.890 .000$

Hemoglobina (g/100 ml) $\quad 15,6$

Valor globular ........ 0,9

Leucócitos $/ \mathrm{mm}^{3} \ldots \ldots \ldots . \quad 7.000$

Neutrófilos $(\%)$ :

Metamielócitos ........... 0

Bastonetes .............. 6

Segmentados ............ 46

Eosinófilos . . ............. 2

Basófilos . .............. 0

Linfócitos (\%):

Típicos .............. 40

Monócitos . . ............ 6

\section{TRATAMENTO}

Consistiu na administração de drágeas de dez miligramas de deidroemetina (Ro $1-9334 / 20$ ) * na dose de 3 drágeas após 


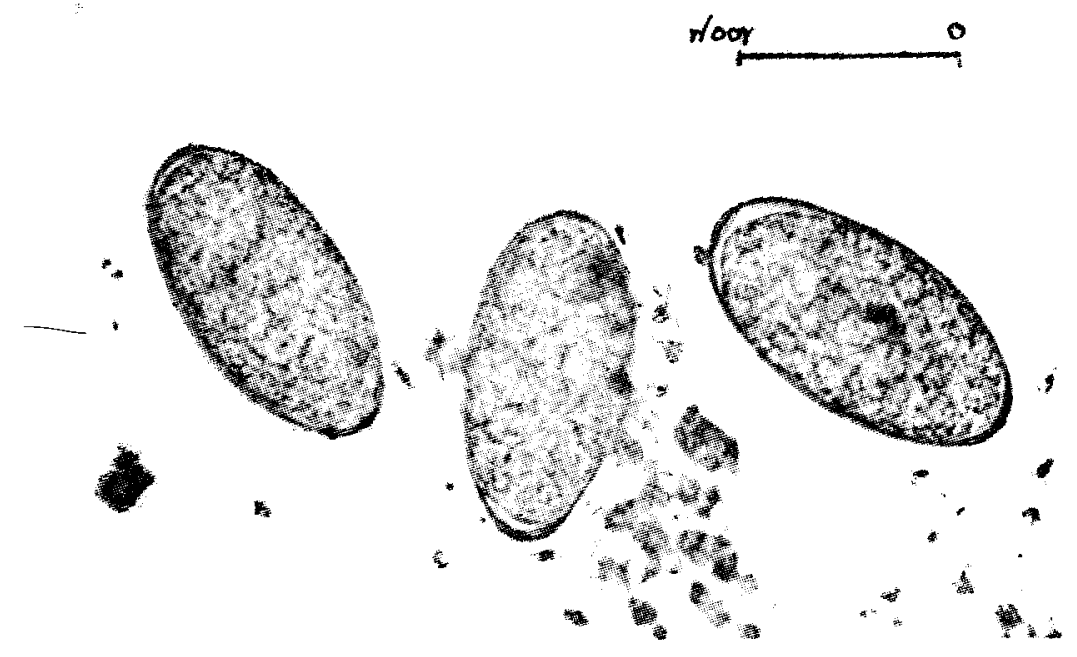

Microfotografia dos ovos de Fasciola hepatica encontrados nas fezes da paciente $M$. G. S.

o desjejum e 2 após o jantar, durante 10 dias. A tolerância foi satisfatória, tendo a paciente completado os dez dias de tratamento sem acidentes: um mês depois a paciente não apresentava mais os sintomas de que se queixava anteriormente

No início do mês de abril foi repetida a entubação duodenal, sendo efetuada a pesquisa cuidadosa de ovos de $F$. hepatica nas biles A, B e C com resultados negativos. O exame parasitológico das fezes efetuado nessa ocasião, foi negativo e, repetido meses depois, resultou novamente negativo.

\section{COMENTÁRIOS}

Dos dados expostos resulta altamente provável que a paciente tenha se infectado em Cornélio Procópio, na chácara pertencente ao Colégio Nossa Senhora do Rosário.
A taxa normal de eosinófilos encontrada na paciente não é de causar espécie pois, como acentuaram Gehrung e col (1) ao se referirem à eosinofilia na fasciolíase: "tem grande valor se está elevada e por si só, em presença de dispepsia, permite autorizar a suspeita diagnóstica de distomatose, porém èste importante sinal se encontra presente sòmente em $77 \%$ aproximadamente dos casos".

A primazia do uso de deidroemetina no tratamento da fasciolíase humana cabe a Pautrizel e col. (4), que a administram a 53 pacientes por via parenteral na dose de $1 \mathrm{mg}$ por quilo de pêso e por dia, durante dez dias, com bons resultados.

No caso que ora relatamos a paciente foi medicada com deidroemetina sob a forma de drágeas contendo dez miligramas da droga, na dose de três drágeas após o desjejum e duas após o jantar, durante dez dias, tendo sido alcançada a cura clínica e a cura parasitológica.

\section{SUMMARY}

An autochtonous case of fascioliasis hepatica, probably acquired in cornélio Procópio, (Paraná, Brazil), is described, with recovery after trealment by dehyäroemethin (Ro $1-9334 / 20$ ) during 10 days.

\footnotetext{
* Agradecemos a PRODUTOS ROCHE QUimicos E FARMACEUTICOS pelo fornecimento do medica. mento.
} 


\section{BIBLIOGRAFIA}

1 - GEHRUNG, E. et alii - "Un caso de distomatoses (fascioliasis) hepática sin eosinofilia sanguínea". Bol. Chileno de Parasit., 22: 37-40, 1967.

2 - HARDMAN, E. W.; JONES, R. L. H. \& DAVIES, A. H. - "Fasciolíasis a large outbreak". British Medical Journal, 3: 502-505, 1970.

3 - MATTAR, F.० J. A. \& AMARAL, A. D. F. "Sôbre um caso humano de fasciolíase hepática". Folia Clínica et Biologica, 36: 56-67, 1967.

4 - PAUTRIZEL, R. et alii - "Traitemente de la distomatose a "Fasciola hepatica" par la dèhyđroémètine" Presse Medicale, 72: 979-982, 1964.

5 - SANTOS, L. DOS \& VIEIRA, T. F. - "Considerações sôbre os sete primeiros casos de fasciolíase humana encontrados no Vale do Paraíba, Estado de São Paulo". Rev. Inst. Adolfo Lutz, 25/27: 95-109, 1965/67.

6 - SANTOS, L. DOS \& FRANÇA, ILDEU - "Descoberta dos primeiros focos dos hospedeiros da Fasciola hepatica no Estado de São Paulo". Resumo dos trabalhos do $18 .^{\circ}$ Congresso Brasileiro de Higiene, pg. 102, 1970. 